\title{
Trainees' Personal Characteristics in the Learning Transfer Process of Permanent Online ICT Teacher Training
}

\author{
Fernanda Fauth * (D) and Juan González-Martínez
}

check for updates

Citation: Fauth, F.

González-Martínez, J. Trainees' Personal Characteristics in the Learning Transfer Process of Permanent Online ICT Teacher Training. Sustainability 2022, 14, 386 https://doi.org/10.3390/su14010386

Academic Editors: Julio Ruiz-Palmero and Melchor Gómez-García

Received: 10 November 2021 Accepted: 29 December 2021 Published: 30 December 2021

Publisher's Note: MDPI stays neutral with regard to jurisdictional claims in published maps and institutional affiliations.

Copyright: (C) 2021 by the authors. Licensee MDPI, Basel, Switzerland. This article is an open access article distributed under the terms and conditions of the Creative Commons Attribution (CC BY) license (https:// creativecommons.org/licenses/by/ $4.0 /)$.

\author{
Department of Pedagogy, Faculty of Education and Psychology, University of Girona, 17004 Girona, Spain; \\ juan.gonzalez@udg.edu \\ * Correspondence: fernanda.fauth@udg.edu
}

\begin{abstract}
The aim of this study was to identify any personal factors that may facilitate the initial transfer of learning among students taking a permanent online ICT training course for teaching staff. Some deductive categories were created based on previous studies, and with the help of the NVivo software and its triangulation, a qualitative analysis of the three data sources-two reflective training activities completed by the subjects and an interview-was used to determine the relevance of some of the identified personal characteristics in the transfer process occurring within the context of distance techno-pedagogical training. Among them, we highlight four relevant ideas for transfer in the context: participants' motivation to innovate in their classes with the use of technologies; selfefficacy, characterized as confidence acquired by the subjects to carry out online training; previous training and professional experiences; and the analysis of their training needs in relation to the critical and reflective use of ICT. We also confirmed that the favourable reaction of the subjects to these factors can serve as an indicator of a possible transfer and that online ICT training should continue to seek to design activities that have positive results in relation to these aspects.
\end{abstract}

Keywords: learning transfer; ongoing teacher training; online mode; personal aspects of the subjects

\section{Introduction}

With the accelerated advance of online training actions, especially within the context of ongoing teacher training, it is important to know how such courses are designed to meet the challenges of society. The knowledge society is in is in constant transformation, and education must accompany these changes and respond to those needs, such as the lack of sustainability in the use of educational resources and technologies [1].

Therefore, thinking about meeting these needs, the Sustainable Development Goals (SDGs) of the 2030 Agenda, adopted by the United Nations in 2015, emphasize quality education (Goal 4) as a resource for improving the lives of people and sustainable development.

As such, this research understands sustainability as a transversal commitment allied to teacher training. That is, it is important that they are duly trained with digital skills to offer an equivalent education with the advancement of technology and in possession of the necessary resources for the use of sustainable technologies in their classes [1,2].

The education system will only be able to address these challenges with well-equipped, committed teachers who are willing to innovate and not only trained but also able to transform that competence into actions for improvement. Thus, we believe in the relevance of determining whether ongoing teacher training offers the acquisition of these competences and whether they are effectively put into practice in pedagogical action. To this end, intending to improve the teaching function, we found as an evaluative proposal the process of transfer of learning and its factors (explained in the following section).

Therefore, research on this type of training is essential if we are to know how teachers apply the learning they have acquired in their daily work. This will make it possible, in 
the future, for educators or course designers, based on the evidence of these studies, to propose more effective training for this process.

\section{Literature Review}

\subsection{The Learning Transfer Concept}

According to the study conducted by Baldwin and Ford [3], the concept of transfer can be determined as the degree to which students successfully and continuously apply the knowledge, skills, and attitudes acquired in a training action [4-8]. Thus, the aim of studying transfer is to find evidence that the new skills and knowledge acquired in teacher training are applied to the situations faced in work environments in an adapted and flexible way [8].

Despite transfer now being old as a concept, its theoretical basis has been identified in the most relevant recent research in the field [4-9]. According to the aforementioned researchers, transfer can be described in terms of input and output factors and involves two conditions. Input factors are those related to individual characteristics, the training design, and the work environment, and output factors are learning outcomes and retention [10].

Regarding the two conditions, the first is generalization. Generalization can be understood as the effective application of learning in contexts or situations other than the scenario in which it was acquired. The second one is maintenance, and it refers to the change resulting from the learning experience that persists over time $[4,5]$.

As already mentioned, we can highlight the theoretical model developed by Baldwin and Ford [3], an irrefutable reference point in empirical studies on transfer [4-9]. This proposal identified three groups of factors that can stimulate or inhibit the learning transfer process and that are used in research both in the business and educational fields: the design of training, the aspects of the individual, and their work environment.

Based on this model and considering that this research relates to personal factors pertaining to the subjects, other researchers have reaffirmed the relevance of said factors to the transfer process in both general models and those related to teacher training. Examples are as follows: motivation $[3,4,11,12]$, experience $[5,12,13]$, needs analysis $[5,14]$, and selfefficacy $[4,5,11]$

\subsection{Learning Transfer in Ongoing Teacher Training}

In recent years, the main studies on transfer have been conducted with respect to evaluating programmes in the field of business training [10]. Thus, Feixas et al. [6] stated that research on transfer in the context of teacher training and in higher education is still very new and should continue to be developed.

Within the field of higher education, ongoing training is considered to be a tool for teachers' professional development and, consequently, for improving the quality of education [7]. One of the primary missions of higher education is to train professionals according to the needs of society and therefore promote professional development among teachers [15].

Cano [16] also stated that for teacher training to be generalized, one of the conditions of the transfer process is for the training to enable teachers to reflect on their practice in order to adapt and apply what they have learnt to their reality and context. Regarding personal aspects, transfer is facilitated when motivation and trust are worked on together with the more technical learning objectives: a teacher who feels committed and trained to be an agent of change is more likely to implement teaching innovation.

In the context of ongoing training, transfer is characterized by a longitudinal process that occurs throughout training, not only at the end of or sometime after it $[17,18]$, and can even be influenced by prior intention to transfer the new learning [9].

Regarding online learning, only a few studies have established the determining factors in the process of e-learning training. From the point of view of emotional aspects, distance training generally requires greater self-management than face-to-face training $[13,14]$. 
Additionally, such training is generally very technological in nature, unaccompanied by specifically pedagogical goals [19].

Based on the research already carried out regarding personal aspects in this type of training, it is essential to link it to the working reality of participants by acknowledging their particular needs, regulating their emotions and thus ensuring trust $[9,14]$, satisfaction, and motivation at the time of transfer $[13,20]$. Prior experience or training must also be taken into account, which, if positive, can represent a source of motivation, contributing to more effective learning and a greater intention to change the working context [13].

\section{Materials and Methods}

\subsection{Paradigm, Aims, and Questions}

This article is the result of a first phase of a more extensive investigation aimed at determining what type of methodological practices in distance training favour a greater transfer of learning in the context of ongoing teacher training. At this point of the study, our specific objective is to analyse which personal factors have the greatest incidence in the initial transfer of learning for the students involved in the online techno-pedagogical training investigated here.

Consequently, the guiding question that we propose to answer with this work is: Which of the students' characteristics facilitate a greater initial transfer of learning?

\subsection{Characteristics of the Context and the Sample}

The context of our research is ongoing online teacher training in the Master's in Education course offered by the Universidad Europea del Atlántico. This training consists of a master's degree in Education, which lasts two years and comprises a common block of subjects for teacher training and specialization with emphasis on ICTs in Education.

The studied group, made up of approximately 40 students, started the course in February 2018 and had an expected end date of February 2020. The group was selected as, at the time of data collection, they had completed the reflective activity known as Starting Point, which takes place in the first weeks of the course; in addition, they had also completed the specialization subjects of the course (five subjects with the theme of ICTs in education) and submitted the corresponding Portfolio, both evaluations being used as a data source (which are detailed in the Section 3.3 below).

Of the whole group, we contacted those who had already completed their evaluations, listed as a source of data in the previous paragraph. Finally, 10 students agreed to participate in the research and signed an informed consent form.

Of the 10 subjects studied, nine were female and one male. The average age of the participants was 42 , with an average of 13 years working as a teacher. The participants' six countries of origin were Argentina, Colombia, El Salvador, Honduras, Mexico, and Nicaragua.

Half of the teachers had qualifications in the field of education, with degrees in English and mathematics. The rest were either qualified in the field of health, with degrees in subjects such as psychology and medicine, or computer systems engineering. Half of the participants worked as university professors (due to the context of their countries, which do not require prior higher education training) and also in online teaching, while the rest worked in primary education or ongoing teacher training.

\subsection{Methods and Data Sources}

The nature of information on transfer in most evaluation studies is perceptual, based on reports of personal experiences that represent new knowledge or skills acquired in training actions and address the application of learning in practice [10,21].

Consequently, as data sources, we have used two training activities from the master's course itself, carried out at different times, one at the beginning and the other in the final stage, which we subjected to a qualitative analysis. In addition, we interviewed the subjects three months after the second activity. 
For ongoing online training, the transfer process does not occur at a precise point in time, that is, it can take place at the end of the training or from a prior intention to transfer in parallel with the training [10], which matches the method of analysing activities at the beginning and throughout the course.

As a first source, in the document referred to as Starting Point, the students answer questions that collect their training and professional experiences before starting the master's degree, as well as their needs and expectations concerning training.

This activity is considered a first stage of the Portfolio, an educational tool that offers the opportunity to continuously reflect on training activities and experiences in real situations that involve students in new approaches, doubts, and reflections on their training process [22].

In the Portfolio, the second source of data, the students described the samples of learning they considered to be most significant and representative of the training process they were undertaking in the specialisation of the course, returning to the reflections elaborated at the beginning of the course in the Starting Point, as well as critically analysing how this knowledge and these skills were having an impact on their training process and their teaching practice. We know that transfer must be encouraged through reflection on what has taken place, by what means, and for what purpose [16,23], which justifies the choice of these activities as a source of data.

Following this, an online interview was conducted with each subject using a previously prepared guide. These interviews were then transcribed and used to analyse the documentary data and the interviews in the NVivo program.

For the interviews, chosen as a resource for questioning the subjects' point of view and helping them with the perception of the situations in which they act [24], the guide was designed with questions related to the design of the course and the working environment, as well as addressing questions focused on personal aspects. The latter enquired about subjects' academic training, work experience, prior experience with ICTs, and motivations or aims for the training. Finally, we asked them about how they intended to transfer the learning acquired in the master's specialisation in relation to the subjects on ICT in education.

\subsection{Data Analysis and Codebook}

The analytical procedure was based on qualitative content analysis, which allowed us to subjectively interpret the content of the textual data through the systemic classification process of coding and identifying themes or patterns [25].

Considering previous theory and research on the process of transfer of learning, we chose to use a direct approach to content analysis [25]. In our case, we took soft categories from the previous conceptualization, derived from the relevant research results, described in the theoretical framework.

Below is the final codebook applied using NVivo software (Table 1).

Using the classification of data according to the previously defined aspects and factors, it was possible to relate them in time for each instrument and with the characteristics of each subject's profile. From the definition of the categories, the ICT-focused themes emerged as we coded the data, due to their relevance to our context of online ICT technology skills training for teachers.

Our study considered the characteristics, perceptions, and assessments of active participants in the training process as informants of the changes implemented in their pedagogical practices through the use of ICTs from the training carried out.

The strategy for validating the data involved their methodological triangulation, that is, a comparison of the different data sources: in this case, the two training activities of the master's course, at the beginning and at the end of the course, and the interview conducted three months after the second activity. According to Stake [26], triangulation allows a precision of the data, which will not depend on the intention to analyse them well or on intuition. 
Table 1. Codebook employed during the NVivo analysis with the categories used.

\begin{tabular}{|c|c|c|c|}
\hline Categories & Studies & Description & Codes \\
\hline Personal motivation & $\begin{array}{l}\text { Baldwin and Ford. [3] } \\
\text { Blume et al. [4] } \\
\text { Burke and Hutchins [12] } \\
\text { De Rijdt et al. [5] }\end{array}$ & $\begin{array}{l}\text { Factors that influence } \\
\text { and stimulate the } \\
\text { individual to perform } \\
\text { certain actions }\end{array}$ & $\begin{array}{l}\text { enthusiasm, interest, } \\
\text { predisposition to } \\
\text { change and innovation }\end{array}$ \\
\hline Self-efficacy & $\begin{array}{l}\text { Blume et al. [4] } \\
\text { De Rijdt et al. [5] } \\
\text { Holton et al. [11] }\end{array}$ & $\begin{array}{c}\text { Judgements } \\
\text { individuals make } \\
\text { about their } \\
\text { competency to } \\
\text { perform defined tasks }\end{array}$ & $\begin{array}{l}\text { confidence, security, } \\
\text { determination, effort }\end{array}$ \\
\hline Previous experiences & $\begin{array}{c}\text { Burke and Hutchins [12] } \\
\text { De Rijdt et al. [5] } \\
\text { Martins et al. [13] }\end{array}$ & $\begin{array}{l}\text { Significant training } \\
\text { and professional } \\
\text { experiences prior to } \\
\text { starting the master's } \\
\text { degree }\end{array}$ & $\begin{array}{l}\text { previous conceptions, } \\
\text { experiences with ICTs }\end{array}$ \\
\hline Needs analysis & $\begin{array}{c}\text { De Rijdt et al. [5] } \\
\text { Quesada et al. [14] }\end{array}$ & $\begin{array}{l}\text { Linking the training to } \\
\text { the specific needs of } \\
\text { the participant's and } \\
\text { career development }\end{array}$ & $\begin{array}{c}\text { training deficiencies, } \\
\text { challenges, difficulties, } \\
\text { goals, professional } \\
\text { objectives }\end{array}$ \\
\hline
\end{tabular}

Using the data collection instruments, we were able to identify those subjects who provided concrete and detailed reports of some experience of applying the learning acquired in the course to their pedagogical practice during the preparation of the Portfolio or in the interview.

Taking this observation into account, we analysed the characteristics and personal factors identified in the two groups (subjects who transferred and those who did not) to determine similarities or differences that could explain the determining factors for the specific transfer that had occurred to date (or, failing that, the absence of transfer).

In the following, we present the categories analysed, supported by fragments of the Portfolios, Starting Point, and interviews that provide evidence of the transfer or the intention to carry it out, confirming the validity.

\section{Results}

\subsection{Personal Motivation}

Another aspect that proved to be a real facilitator for transfer, as has already been indicated in previous studies, was personal motivation.

Personal motivation in this category is defined as the effort made by the trainee to use the skills and knowledge learned in training in a real work situation [12].

Of those subjects who already had personal motivation at the start of the course, detected in the Starting Point analysis, the majority reported transfer while studying the subjects taught in the course in their Portfolio.

Many of the students already mentioned at the beginning of the course that they felt motivated to apply in their practice the knowledge that would be acquired in the course, as can be seen in the following accounts from the Starting Point:

"My expectations are focused on learning. Learning to teach using new technologies and developing undergraduate and graduate programmes that incorporate new ways of teaching and learning, taking into account the construction of knowledge and respecting the different ways in which students learn, including peer group cooperation in activities to enrich teaching". (Starting Point-subject I)

"As an education professional, I am committed to constant updating and innovation, and this motivated me to opt for this master's degree in education". (Starting Pointsubject F)

A further relevant observation was that most of the participants reflected on the motivation to make changes and transfer the acquired knowledge reported in the Portfolio 
to practice, suggesting that the course is designed with activities that motivate and facilitate the predisposition to change in their practice, as illustrated by the following reflections:

"Finally, it is worth noting that I am very happy with the master's degree, it's a different experience that has given me a lot of energy to carry out fundamental changes required by the globalized world we live in. Based on everything I've studied so far, it would be almost impossible to continue working without thinking about making continuous changes that improve my teaching practice". (Portfolio-subject D)

"It allowed me to understand my limitations in putting into practice what I learned in my workplace, due to lack of resources because of different social and economic situations. But still, it motivated me to be more resourceful and creative to achieve my class objectives". (Portfolio-subject $\mathrm{H}$ )

On the other hand, in general, the subjects without concrete transfer did not present any prior personal motivation either. In the portfolio, they also did not indicate that they were motivated to transfer, did not present concrete evidence of the transfer, or only presented the intention to transfer.

In the interviews, almost all of the subjects considered the training to have motivated them to make changes to their pedagogical practice. The subjects who had already reported transfer expressed being motivated by what they had already changed in their practice, as can be gleaned from the interview with subject I:

"A lot, so much so that that I applied it to a lot of courses and activities. I designed a blended learning course this year for X University, which is $2000 \mathrm{~km}$ from where I live. We travelled there once a month for the face-to-face activity and then during the three interceding weeks we did activities on the virtual campus, which involved deciding the objectives, the target competences, which resources to use, it wasn't easy, it wasn't easy for the doctors to engage in online learning, but hey, it was an experience that inspired me a lot because it meant I had to compile teaching guides, to think about resources, interact with the students about their questions, because the learners don't say: "Well, I'll do this and that's it", but they begin to ask questions that perhaps you hadn't anticipated. The truth is it was very enriching". (Interview-subject I)

In the few cases where it was not possible to detect changes in the participants' practice, it was noticeable from their interviews that they were at least encouraged by the possibility of innovation and improving their practices:

"Yes, I'm always encouraged and enthusiastic to find new tools that help me improve my teaching practice and the use of ICTs". (Interview-subject G)

\subsection{Self-Efficacy}

The category of self-efficacy is here defined as an individual's general belief that he/she can change his/her performance when he/she wants to [11]. Among the participants who expressed transfer precisely, they declare themselves capable and confident in using ICTs during the course:

"After concluding this block of subjects; I find myself more empowered to do online training and use applications and tools that enhance the use and mastery of ICTs in the teacher training that I plan and execute from my workspace". (Portfolio-subject F)

"Since the beginning of the specialisation I have felt very confident in my training and teaching practice in the area of Computer Science, I see great progress in my training process, as I have reinforced my knowledge regarding ICT in the classroom, not forgetting all the knowledge acquired in the Master". (Portfolio-subject E)

This aspect confirms the importance of self-efficacy in managing ICTs as a facilitating factor for transfer and that above and beyond the student's cognitive commitment, it is important that the course also provides tasks that stimulate students and provide them with confidence, as illustrated by the following stories: 
"Personally, as a student and teacher, although I am a capable user of technology, taking a step forward in thinking and incorporating new knowledge both for learning and for its application as a pedagogical instrument involved a mental and procedural openness that I am truly enjoying. Doing the master's degree daily is a very pleasing experience, it makes me happy and connects me with what I like: teaching and learning". (Portfoliosubject I)

"It motivates me to move forward and to be more committed in my work, not only putting into practice the planning and organisation of each class but also improving in the development of intellectual competences where I can update myself with the information, which I will then share with my students, through the mastery of concepts learned in these two years of the master's course". (Portfolio-subject E)

Equally, in the group that did not apply the learning, the feeling of confidence was mentioned in the interview, suggesting that transfer did not occur due to some other external factor:

"I definitely already feel more confident about knowing what I can use, what kinds of tools I can start to include with certain students, which platforms they will need, for example, which to use to search and to analyse which are the easiest. If they are well equipped at a pedagogical level, then that already makes me feel more confident in what I am doing". (Interview-subject J)

It was also revealing that all of the participants expressed their intention to transfer the knowledge to practice in their Portfolios and interviews. All of the Portfolio reflections are directed to transfer the acquired learning, which possibly shows that the subjects they had studied allowed participants to reflect on their practice in relation to the acquired learning and aroused interest and commitment in change, as the following excerpts illustrate:

"I also feel committed to applying the appropriate methods and strategies to my students' training process, since I have to rethink the traditional teaching activities, to expand and complement them with new activities and learning resources that can generate actions aimed at integrating ICTs to improve school management". (Portfolio-subject E)

"It always made me think that I have to keep going, I have to keep studying and improving. I am waiting to finish the thesis so I can dedicate myself a little bit more to the research of different, other ICT tools that I want to apply in my classroom". (Interview-subject G)

Therefore, we can consider that self-efficacy was a significant aspect of the transfer process, due to the detection of confidence among those who made the transfer.

\subsection{Previous Experience}

In relation to previous experiences, here, we refer to the professional and training experiences of the participants concerning ICTs.

Almost all of the subjects already had some prior training experience with ICTs. However, from a technological perspective, this experience was not specifically ongoing teacher training in ICTs with a pedagogical approach for its application, as the following report indicates:

"We acquire technological knowledge from courses that are offered in the computer rooms at the schools where we work, and these are run by the school's IT technician. This means that they present us with a resource and tell us how it works and all the benefits it has; we marvel at it, but when we reflect on a practical and easy way of using it in our groups, we realize that we don't know when we might make use of it and if we try to do something with it we spend many hours in the attempt. This happens too often and the result is that, despite taking courses and workshops, our classes have very few substantial changes in them". (Interview-subject B)

However, a large proportion of the subjects who did implement transfer at the beginning also reported feeling secure and confident in the use of ICTs due to their previous 
training or practical experience, as indicated below. This leads us to believe that both are facilitating factors for transfer:

"I was looking for a way to find this training, but on my own, learning through tutorials and things like that, but in reality the one that has worked for me is this one, the master's degree". (Interview—subject E)

Regarding teaching experience, those who showed more evidence of transfer had twice the experience of those who showed no evidence of it. As for the length of time working at the same institution, the first group also had a significantly longer means time than the second group. The above findings suggest that both professional experience and working in the same environment are determining factors that result in a greater tendency towards learning transfer. This may be due to teachers being more familiar with the reality of their environment, receiving more trust or support from the institution, or other factors related to the working environment.

In contrast, recently qualified teachers or those who had not been long at the institution reported little or no transfer. As an example of this, we find the following report by one of the subjects who did not implement learning transfer, who had been a teacher for four years and only been working at the same institution for one year:

"As it's a new job, I need to know how the place works, but, perhaps also on a personal level, I need prior approval to start something new, to know whether I'm doing things right. It's like I need that prior feedback before I fully throw myself into a project". (Interview-subject J)

\subsection{Needs Analysis}

In relation to the needs analysis, this article focuses on how participants are aware of and report on their personal, training-related, and professional development needs [14].

Regarding the importance of being aware of the specific need for training that leads teachers to engage in the learning experience, the vast majority of participants suggested this was the acquisition of pedagogical knowledge in the application of ICTs, as revealed below:

"Sometimes I feel that I have a lot of experience as a teacher in a subject that is part of one of the master's degrees currently taught at Faculty X, but when it comes to designing my pedagogical actions I find shortcomings in my theoretical-teaching knowledge". (Starting Point-subject D)

Among those participants who worked in higher education, a common factor was also the need for professional development, a qualification to endorse their position, probably because it is a level of education that requires its teachers to be more up to date:

"Although I have been working by trial and error for years, I sense I need a theoretical framework and academic support to see what I have been doing well or badly, what I should change or adapt, and thanks to this degree I can demonstrate to my current and/or potential employers that I am capable of training future trainers". (Starting Point-subject A)

We also observed that all the members of this group hold some leadership or coordination position in their working environments, which can also be a facilitating factor for transfer, since they have a position of responsibility in an institution and have both a personal and social commitment to it:

"[ ... ] That was the main reason that encouraged me to do this master's degree; I wanted to carry out my coordination work with greater efficiency and quality". (Starting Point-subject B)

The participants' accounts revealed that the course enabled them to feel empowered with regard to ICT theory, given that the majority of them considered it to have met the training need of acquiring pedagogical knowledge, as indicated by the following reflection:

"When starting this master's degree, my main aim was to learn and expand my pedagogical strategies, but as I was doing each subject, I set myself a new goal, which was 
to share my knowledge with others and make all that pedagogical and didactic material known to other teachers, perhaps training other trainers in topics such as ICTs". (Portfolio-subject $\mathrm{H}$ )

In the reflections described in their Portfolios, the teachers moved on to the perspective of transfer, specifying challenges based on experiences with ICTs in the specialized subjects:

"After the master's degree, I hope to begin to build and innovate proposals from my work space that meet educational training needs, where I contribute the knowledge acquired and can help other teachers to use and exploit all the resources that the Web currently offers us. I am considering the following challenges that arose from the experiences shared in this document: creating tools such as blogs, wikis and websites that serve as support for the teachers I train from my work space, which would mean I'm applying and putting into practice the knowledge acquired on the Master's in Education". (Portfolio-subject F)

During the interviews, when they were asked about whether they needed to acquire digital skills, the vast majority of the participants said they did, that their needs had been addressed, and that these were now directly related to the specific application of learning in the workplace. In other words, aligning this awareness of the need for training with specific work in that area during the learning experience results in the learned content beginning to be transferred in the short term, as one would expect. An example of this is found in the following excerpt:

"My aim is to continue with my academic and personal training through different workshops or certifications that can be found online or face-to-face workshops/courses in order to learn about applying ICT tools in the classroom, assertive communication, successful methods for collaboration in group, among others". (Interview-subject G)

"Yes ... definitely. My goal when I started, and in the previous job I was in, was to start doing absolutely everything online, make all the training that people received on a face-to-face level virtual, but obviously as a psychologist I had no training and couldn't understand many things. At that time I felt that need, and I said to myself I need to get more training myself before trying to train other people". (Interview-subject J)

Exceptionally, some participants also reported feeling capable of innovating in practice but needing constant ongoing training:

"I think it has helped me, but it's not enough. I think you have to have the determination to continue investigating on your own because in reality the tools change from one day to the next, all of the training, the certifications, you have to find out how to learn more, so I think it's a starting point but no, you can't stop there". (Interview-subject G)

This leads us to think that although the goal of acquiring pedagogical knowledge was achieved in the course, a question remains of whether there is a lack of practical activities that help the student adapt the content more to their context or whether it is the working environment that makes application difficult, as this excerpt would suggest:

"No, I actually did courses and then nothing afterwards, it bothered me, but I learned because Faculty X has a virtual campus, but small courses, simple things, and so I did simple things, not with the pedagogical structure in the way I learned on the master's course". (Interview-subject I)

On the other hand, with regard to the few participants who did not implement learning transfer, we observe that all of them did express the expectation to do so in the Starting Point document. That said, a minority mentioned in the interview that their needs at the beginning of the course were more directly related to working environment factors, that is, to improved job opportunities or qualifying:

"Actually, I had the expectation of obtaining something that would attest to the fact that I was, sorry for the lack of humility, that I was doing things right, since I didn't have any references if I wanted to present my CV for a job". (Interview-subject A) 
It is also relevant for the transfer process that the course makes it possible for almost all the students to prepare the proposal for their final master's project (a monographic work within the specialized field of ICTs) in relation to their work environment. Undoubtedly, this points to the objective of transferring the learning from the course in a way that is adapted to their working reality and meets the student's personal needs. Almost all the participants elaborated, either by a continuous training proposal or by implementing ICT in the teaching-learning process of their areas of activity, as has been evidenced, for example, in the Portfolio of subject $\mathrm{H}$ :

"The result and/or fruit of doing all of the recommended activities, forums, tasks, guides in this field of specialization, comprise the objective of the master's degree, which should be reflected in my actions as a teacher and in my pedagogical practice at school. In addition, the final degree project will reflect that pedagogical action, the product of all that has been learned and what has been achieved in not only professional but also work-related and personal training".

As a pending topic at this time, in relation to what we have said about the participants not having completed their master's degree, in the next stage of data collection, it would be useful to investigate whether the proposals were effectively put into practice in their working contexts, thus concretizing the transfer of learning.

\section{Discussion and Conclusions}

By way of conclusions, we can affirm that the results corroborate what was previously indicated in the literature regarding personal characteristics that facilitate the transfer process in relation to ongoing online training, although in the specific context addressed here of technological training in online ICT skills for teachers, a field that is still new in transfer research.

From there, if the question we asked ourselves was which personal factors are most conducive to the transfer of learning in the context of online techno-pedagogical training, we highlight the relevance of four factors that will be analysed below.

The aspect of personal motivation was a facilitator $[6,13,20]$, as most of the subjects who reported the transfer reported feeling motivated to make changes in their practice. Here, we highlight the motivation factor related to the learning acquired in relation to ICT, how to innovate in their classes from a reflective use of ICT, and how to overcome the difficulties of resources not available in their labour reality.

The accounts have been observed during the course with the elaboration of the Portfolio and in the interview. However, some participants already reported the motivation to transfer at the beginning of the course with the Starting Point activity. In this case, the process may have been influenced by the prior intention to transfer new learning [9].

In relation to the category of self-efficacy, it was possible to find evidence of the transfer of the subjects with the development of the feeling of confidence and ability to manage ICT and make the changes conquered throughout the course. Here, again, those subjects who reported feeling confident to use the campus or those who overcame feelings of fear or insecurity with online training $[9,13]$ also stand out for transfer in this context.

We were also able to detect that prior teaching experience and time spent working at the same institution determine opportunities for transfer to take place, since the group that implemented transfer was more experienced and had worked longer in the same environment [13]. In addition, previous training experiences, when positive, can function as facilitators for transfer [13]. However, in this case, the previous experiences helped with confidence in the technical handling of ICTs but did not address the pedagogical and critical aspect of their use sought by the participants with the training.

From the category of needs analysis, we aimed to identify whether, aware of their personal needs and their working reality, the participants felt their needs were met in online training and the transfer was facilitated.

We would note that most of the study participants were looking for training with a pedagogical approach, because even those who already had prior training in ICTs stated 
that the usual courses were very much (excessively) focused on technological components (technological literacy, in fact) and not on the exploitation of ICTs for teaching purposes [19]. In this sense, the lack of training that led them to seek out a course was clearly related to acquiring pedagogical knowledge in the use of ICTs, which was addressed throughout the course and correlated with a desire to put learned content into practice. The participants adopted this idea of moving towards real action (or transferring) as the new challenge after taking the course. This reaffirms the importance that courses attend even more to their students' training needs to help them overcome these obstacle factors by connecting more to their workplace reality [14].

In the same vein, we can refer to the type of institution and job, bearing in mind that most participants who worked in higher education or ongoing training and who held leadership positions began to apply knowledge in their practice and implement transfer before others. The vast majority of these participants were looking for a professional development opportunity in training. They therefore already had some intention of improving their practice through the transfer of learning $[7,15]$. However, in addition to personal characteristics, it is necessary to know more about their working realities to specify to what extent this influenced the transfer process.

Here, it is also important to highlight that, apart from personal factors, it is plausible to think that the course design met the participants' pedagogical training needs, enabling their reflection on their practice and encouraging learning transfer $[9,22]$. This would explain the feeling of capacity and the motivation to improve their practice through the use of ICTs expressed by practically all of the participants in their Portfolios and interviews, as well as the approach to transfer in the master's final project, which corroborates with previous studies that indicate that a final project or the creation of a product related to the implementation of what has been learned in the training improves the conditions for transfer $[7,16,20]$.

In conclusion, we would confirm that the participants' reactions serve as an indicator of a possible transfer and that online training should continue to aim to design activities that have positive results concerning these aspects (motivation, auto-efficacy, previous experiences, and needs analysis).

As online teaching requires more self-management than face-to-face teaching [14], by knowing more about motivations, experiences, needs, and feelings generated during training in relation to ICT, we can promote the improvement of educational quality in this training context. The evidence from this study can help with the promotion of a more relevant training process for the transfer of teachers' digital competence learning in online courses, considering the personal factors discussed here.

However, we found that despite the learning results and affective feedback being positive and there being an intention to apply them to working practice, limitations in the working environment can still interfere in the transfer process, regardless of the training context.

\section{Limitations and Further Developments of the Research}

Therefore, aware of the limitations of the study for qualitative research, either because of the small number of participants or the reduced illustration of each category, due to the limitations of the length of the manuscript [27], from the analysis of the categories, the training provides evidence of some factors as facilitators of transfer. However, the intentional work of these factors throughout the course, with the data available to us, does not allow us to determine whether it was effective in terms of improving transfer in the context of the training; in this sense, we will have to continue researching to see if it was not enough, if it needs adjustments in the design to enhance them even more, or if some factor in the work environment did not enable the process.

Based on our analysis of the participants' profiles from this stage of the research, we were able to detect specific personal needs and obtain more precise guidelines so that the course design might be adapted to these profiles in a general and flexible way, once inno- 
vations and sustainable adoption of ICT evolve through modifications based on teachers needs and expectations [28]. Additionally, teachers with positive attitudes who are satisfied with the program organize and develop their professional activity with more personal and sustainable commitment, in addition to improving their digital teaching skills [2].

Therefore, in the next stages of this research, there is an evident need to determine and carry out an in-depth analysis of the most relevant and significant aspects of course design and the working environment for these participants, in addition to the personal factors detected here. The triangulation of these three aspects will allow us to assess and obtain guidelines concerning future educational strategies for ongoing online training and, more specifically, that related to ICT skills.

Author Contributions: The following is the distribution of the different tasks among the research team: Conceptualization, F.F. and J.G.-M.; methodology, F.F. and J.G.-M.; validation, J.G.-M.; formal analysis, F.F.; investigation, F.F.; resources, F.F. and J.G.-M.; data curation, F.F.; writing-original draft preparation, F.F.; writing-review and editing, F.F. and J.G.-M.; visualization, F.F.; supervision, J.G.-M.; project administration, F.F. and J.G.-M. All authors have read and agreed to the published version of the manuscript.

Funding: This research is part of an industrial $\mathrm{PhD}$ project funded by Generalitat de Catalunya (Agència de Gestió d'Ajuts Universitaris i de Recerca, grant number 2018 DI 96). It was funded by University of Girona.

Institutional Review Board Statement: Ethical review and approval were waived for this study, because at the time we collected the data, this process was not mandatory at the University of Girona (reference institution for this project), at the UNEAT (university were the fieldwork was developed), or by the Agència de Gestió d'Ajuts Universitaris I de Recerca (AGAUR) (the funding institution), since this research does not use particularly sensitive human data (only opinions and perceptions regarding public dimensions of life) and does not involve direct intervention or experimentation on humans or living beings. However, the necessary ethical requirements have been respected. For the performance of this study, it has enough to have the informed consent of the subjects. In particular, this informed consent included the introductory text, "I am fully assured that I will not be identified and that the information I provide will be kept confidential. The results will be made available to me at my convenience. The data will be treated confidentially and treated for academic analysis only", thus ensuring the protection of personal data and guaranteeing digital rights.

Informed Consent Statement: All subjects gave their informed consent for inclusion before they participated in the study.

Data Availability Statement: The data presented in this study are available on request from the corresponding author. Because of its personal nature (opinions and beliefs about one's own learning process), despite anonymity, it cannot be openly hosted in a research data repository.

Conflicts of Interest: The authors declare no conflict of interest. The funders had no role in the design of the study; in the collection, analyses, or interpretation of data; in the writing of the manuscript; or in the decision to publish the results.

\section{References}

1. Abad-Segura, E.; González-Zamar, M.-D.; Luque-de la Rosa, A.; Morales Cevallos, M.B. Sustainability of Educational Technologies: An Approach to Augmented Reality Research. Sustainability 2020, 12, 4091. [CrossRef]

2. Baena-Morales, S.; Martinez-Roig, R.; Hernádez-Amorós, M.J. Sustainability and Educational Technology-A Description of the Teaching Self-Concept. Sustainability 2020, 12, 10309. [CrossRef]

3. Baldwin, T.T.; Ford, J.K. Transfer of training: A review and directions for future research. Pers. Psychol. 1988, 41, 63-105. [CrossRef]

4. Blume, B.; Ford, K.; Baldwin, T.; Huang, J. Transfer of training: A meta analytic review. J. Manag. 2010, 36, 1065-1105. [CrossRef]

5. de Rijdt, C.; Stes, A.; van der Vleuten, C.; Dochy, F. Influencing variables and moderators of transfer of learning to the workplace within the area of staff development in higher education: Research review. Educ. Res. Rev. 2013, 8, 48-74. [CrossRef]

6. Feixas, M.; Lagos, P.; Fernández, I.; Sabaté, S. Modelos y tendencias en la investigación sobre efectividad, impacto y transferencia de la formación docente en educación superior. Educar 2015, 51, 81-107. [CrossRef]

7. Feixas, M.; Durán, M.; Fernández, A.; García, M.; Márquez, M.; Pineda, P.; Quesada, C.; Sabaté, S.; Tomàs, M.; Zellweger, F.; et al. ¿Cómo medir la transferencia de la formación en educación superior?: El Cuestionario de Factores de Transferencia. REDU Rev. Docencia Univ. 2013, 11, 219-248. [CrossRef] 
8. Ornelas, D.; Cordero, G.; Cano, E. La transferencia de la formación del profesorado universitario. Aportaciones de la investigación reciente. Perf. Educ. 2016, 38, 57-75.

9. Testers, L.; Gegenfurtner, A.; van Geel, R.; Brand-Gruwel, S. From monocontextual to multicontextual transfer: Organizational determinants of the intention to transfer generic information literacy competences to multiple contexts. Front. Learn. Res. 2019, 7, 23-42. [CrossRef]

10. Fandos-Garrido, M.; Renta, A.; González, J.; Soto, A. Análisis sobre el aprendizaje y la aplicación de las competencias generales en el contexto laboral: Estrategias de colaboración entre la formación profesional, la universidad y la empresa. Educar 2017, 53, 333-355. [CrossRef]

11. Holton, E.; Bates, R.; Ruona, W.E. Development of a Generalized Learning Transfer System Inventory. Hum. Res. Dev. Q. 2000, 11, 333-360. [CrossRef]

12. Burke, L.A.; Hutchins, H.M. Training Transfer: An Integrative Literature Review. Hum. Res. Dev. Rev. 2007, 6, 263-296. [CrossRef]

13. Martins, L.; Zerbini, T.; Medina, F.J. Impact of Online Training on Behavioral Transfer and Job Performance in a Large Organization. J. Work Organ. Psychol. 2019, 35, 27-37. [CrossRef]

14. Quesada-Pallarés, C.; Espona-Bracons, B.; Ciraso-Calí, A.; Pineda-Herrero, P. La eficacia de la formación de los trabajadores de la administración pública española: Comparando la formación presencial con el eLearning. Rev. CLAD Reforma Democr. 2015, 61, 107-132.

15. Cano, E. Factores favorecedores y obstaculizadores de la transferencia de la formación del profesorado en educación superior. REICE Rev. Iberoam. Sobre Calid. Efic. Cambio Educ. 2016, 14, 133-150. [CrossRef]

16. Cano, E. Evaluación de la formación: Algunas lecciones aprendidas y algunos retos de futuro. Educar 2015, 51, 109-125. [CrossRef]

17. Gessler, M.; Hinrichs, C. Key predictors of learning transfer in continuing vocational training. In Working and Learning in Times of Uncertainty, 1st ed.; Bohlinger, S., Haake, U., Helms-Jorgensen, C., Toiviainen, H., Wall, A., Eds.; Sense Publishers: Rotterdam, The Netherlands, 2015; pp. 43-60.

18. León, R. La Formación en TIC del Profesorado y su Transferencia a la Función Docente: Tendiendo Puentes Entre Tecnología, Pedagogía y Contenido Disciplinar. Ph.D. Thesis, Universitat Autónoma de Barcelona, Barcelona, Spain, 2018.

19. Pineda Herrero, P.; Espona-Barcons, B.; Ciraso-Calí, A.; Quesada-Pallarès, C.; Valdivia-Vizarreta, P. Evaluación de la formación eLearning en el Instituto Nacional de Administración Pública: Resultados del estudio MEEL. Gest. Anál. Políticas Públicas 2016, 15, 97-112. [CrossRef]

20. Tomás-Folch, M.; Duran-Bellonch, M. Comprendiendo los factores que afectan la transferencia de la formación permanente del profesorado. Propuestas de mejora. Rev. Electrónica Interuniv. Form. Profr. 2017, 20, 145-157. [CrossRef]

21. Davids, A. La Transferencia del Aprendizaje en Contextos de Formación Para el Trabajo y el Empleo. Ph.D. Thesis, Universitat Rovira i Virgili, Tarragona, Spain, 2013.

22. Esqué-Boldú, S.; Gisbert, C.M.; Larraz, R.V. El uso del e-portafolios en las prácticas del Bàtxelor en Enfermería. Rev. Docencia Univ. 2014, 12, 399-423. [CrossRef]

23. Ortega, P. El profesorado como agente de cambio en espacios de formación continua. REXE Rev. Estud. Exp. Educ. 2008, 13, 73-84.

24. Eisner, E.W. Ojo Ilustrado: Indagación Cualitativa y Mejora de la Práctica Educativa; Paidós: Barcelona, Spain, 1998 ; pp. 81-103.

25. Hsieh, H.F.; Shannon, S.E. Three approaches to qualitative content analysis. Qual. Health Res. 2005, 15, 1277-1288. [CrossRef] [PubMed]

26. Stake, R.E. Investigación Con Estudio de Casos, 6th ed.; Morata: Madrid, Spain, 2010; pp. 94-105.

27. Drisko, J. Writing Up Qualitative Research. Fam. Soc. J. Contemp. Soc. Serv. 2005, 86, 589-593. [CrossRef]

28. Niederhauser, D.S.; Howard, S.K.; Voogt, J.; Agyei, D.; Laferriere, T.; Tondeur, J.; Cox, M. Sustainability and Scalability in Educational Technology Initiatives: Research-Informed Practice. Technol. Knowl. Learn. 2018, 23, 507-523. [CrossRef] 